282

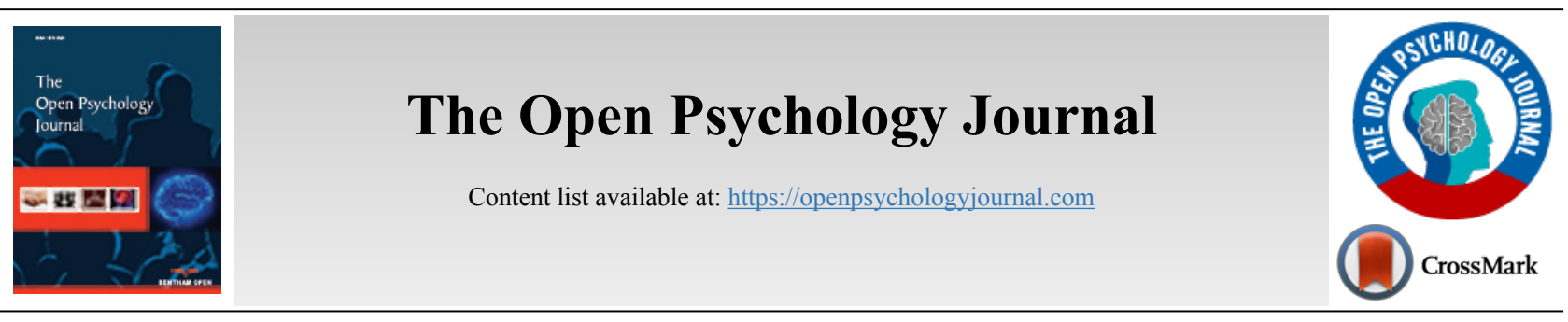

RESEARCH ARTICLE

\title{
The Role of Personality Traits and Situational Factors as Determinants of Aggression
}

\author{
Youssef Hasan $^{1, *}$ and Hanady Eldous ${ }^{1}$ \\ ${ }^{1}$ Department of Social Sciences, College of Arts and Sciences, Qatar University, Doha, Qatar
}

\begin{abstract}
:
Background:

Over the years, different explanations have been given for the difference between personality traits and situational factors regarding how they affect our behavior. The present study investigates the role of personality traits versus situational factors in aggressive behavior.

Objective:

The purpose of this research was to examine whether situations in which participants are made to feel angry are more powerful than personality traits in determining aggressive behavior.

\section{Methods:}

Forty-eight women students from Qatar University $(M=21.73, S D=4.43)$ completed the 200-item ZKA Personality Questionnaire, which measures aggressiveness, neuroticism, activity, extraversion and sensation-seeking, and the 7-item trait anger scale from the Buss-Perry Aggression Questionnaire (BPAQ). Following an experimental situation that triggered anger by an interpersonal insult, the participants were randomly assigned to an anger-induced group (experimental condition) or a nonanger-induced group (control condition). Afterwards, the participants completed the hot sauce paradigm to assess aggressive behavior.

Results:

The results showed a significant difference between the anger and nonanger groups regarding aggressive behavior. However, no significant correlation was found between any facets of the personality questionnaire or the trait anger scale and aggressive behavior.

\section{Conclusion:}

Situational influence is more powerful than personality traits and trait anger in determining aggressive behavior. These findings are discussed based on the debate addressing the influence of situational or person-specific traits in determining actual behavior.
\end{abstract}

Keywords: Personality traits, Situational factors, Interpersonal insult, Trait anger, Aggressive behavior, Hot sauce paradigm.

\begin{tabular}{|l|l|l|r}
\hline Article History & Received: March 03, 2020 & Revised: July 11, 2020 & Accepted: August 11, 2020
\end{tabular}

\section{INTRODUCTION}

Considerable research has been conducted to identify risk factors for aggression. Studies have raised an important question regarding the role of individual differences in aggressive behavior. Previous studies have associated personal characteristics such as self-esteem, narcissism, and personality traits with aggression [1]. However, it is also well known that stressful situations increase aggression [2]. Research has shown that aversive events produce a negative affect, which, in turn, is

* Address correspondence to this author at the Department of Social Sciences, College of Arts and Sciences, Qatar University, Doha, Qatar;

E-mail: youssef.hasan@qu.edu.qa related to aggression [3].

The General Aggression Model provides a useful framework for understanding aggression and situational contributors [4]. The GAM suggests that personal and situational variables are the key inputs that influence aggression. According to this model, personal variables include factors such as gender, genetic predispositions, normative values, personality traits and attitudes. Situational factors include variables that promote aggression, such as provocation, aggressive cues, violent media and the use of drugs. These situational variables can increase state anger [5]. 


\subsection{Situational Factors vs. Personality Traits}

Previous studies have shown that aggression is negatively correlated with conscientiousness and agreeableness and positively correlated with neuroticism, depression, vulnerability, anger hostility, and impulsiveness [6, 7]. A metaanalysis found that trait aggressiveness and trait irritability are related to aggression under both provoking and neutral conditions, while trait anger, Type A personality, dissipation-rumination, emotional susceptibility, narcissism, and impulsivity are related to aggression only under provoking conditions [8].

The role of situational factors in creating provocation or unpleasant feelings that in turn influence aggression by impacting an individual's internal state has been shown reliably in research, specifically relating to hot temperatures [9], physical pain and competition [10], interpersonal insults [11], and social rejection $[12,13]$.

\subsection{The Role of State Anger}

Anger as a negative emotion is triggered by aversive events [3]. It is well known that anger emotion influences driving performance and attentional processing [14], cardiac activity [15], and deception [16]. In addition, it causes headaches, high blood pressure, cardiovascular diseases, increased anxiety, depression, insomnia, and reduced immune system functioning [17].

Concerning its relationship with aggression, previous research has shown that participants in an angry mood displayed more aggressive attitudes than participants in a neutral mood [18]. Recent research has also demonstrated that participants who were made to feel anger had more dominanceseeking and higher levels of aggression [19].

To induce anger in psychology laboratories, experimental psychologists have used several techniques, such as films [20], cover stories (e.g., interpersonal insults) [21]. In the present study, we used an interpersonal insult technique to induce state anger.

The majority of social psychologists accept the statement that the role of the situation is more important than personality in predicting aggressive behavior [22]. The role of the effects of personality traits on aggressive behavior is still limited, with no constant evidence of these effects [23]. However, there has been a greater research focus placed on the impact of situational factors on aggression [24]. One of the most important tasks is integrating both personality traits and situational factors in predicting aggressive behavior [22]. The present study tested both the role of personality traits and situational factors as determinants of aggressive behavior within the same experiment. This study is important because it enhances our understanding of the predictors and mechanisms that determine aggressive behavior.

\subsection{Present Research}

In the present study, forty-eight college women students from Qatar University completed the Zuckerman-KuhlmanAluja Personality Questionnaire and the trait anger scale. Then, they were randomly assigned to either an 'anger' condition or 'nonanger' condition. Anger was induced by using an interpersonal insult. Afterwards, the participants completed the hot sauce paradigm to assess their aggressive behavior. We predicted that the situation in which the participants were made to feel angry would be more powerful than personality traits in determining aggressive behavior.

\section{METHODS}

\subsection{Participants}

The participants consisted of forty-eight women college students $\left(M_{\text {age }}=21.73, S D=4.43\right.$, age range: $\left.17-42\right)$ from Qatar University. The participants were randomly allocated to either an anger-induced group $(n=24)$ or a nonanger-induced group $(n=24)$. The participants did not receive any course credits or payments for their participation. The sampling method employed opportunity-based sampling by asking students within the College of Arts and Science, whether they wished to take part in the study.

\section{MEASURES}

\subsection{Personality Questionnaire}

We used the Zuckerman-Kuhlman-Aluja Personality Questionnaire [25]. The ZKA-PQ is a 200-item personality questionnaire designed to assess an alternative five-factor model. The ZKA-PQ contains five factors:aggressiveness, neuroticism, activity, extraversion and sensation-seeking. Each factor comprises 40 items divided into four facets. Extraversion includes sociability, social warmth, exhibitionism, and positive emotions. Activity involves general activity, work energy, work compulsion, and restlessness. Sensation-seeking encapsulates experience-seeking, thrill and adventure-seeking, impulsivity, and disinhibition. Aggressiveness measures anger, hostility, physical aggression, and verbal aggression. Finally, neuroticism is connected to dependency, low self-esteem, depression, and anxiety. The Arabic version of the ZKA-PQ was used [26]. The responses were rated on a 4-point Likert scale, ranging from strongly disagree (1) to strongly agree (4). The internal consistency of these factors was satisfactory: aggressiveness $(\alpha=90)$, neuroticism $(\alpha=88)$, activity $(\alpha=83)$, extraversion $(\alpha=74)$, and sensation-seeking $(\alpha=74)$.

\subsection{Trait Anger}

Trait anger was assessed using the trait anger scale from the BPAQ [27]. This scale contains seven items. The Arabic version of this scale was used [28]. The responses were rated on a 4-point Likert scale, ranging from strongly disagree (1) to strongly agree (4). The internal consistency was satisfactory ( $\alpha$ $=72$ ).

\subsection{State Anger}

State anger refers to short-lasting outbursts of anger that are temporary. Previous studies have used the interpersonal insult technique to induce state anger in participants [29, 30]. In our procedure, the participants were presented with 20 colored images of various styles of Western clothing and asked to rank the images based on their personal opinion of fashion. Then, they were informed that their choices would be evaluated 
by their peers and vice versa. The researcher provided the images selected by a peer and requested from the participant to write one paragraph on the quality of the participant's choices of fashion ranking. Then, the researcher left the lab with the images selected by the participant to be evaluated by the peer. After five minutes, the researcher returned with the participant's selected images with the feedback made by the peer, along with the text written by the participant about the images selected by the peer. Half of the participants received a text containing negative feedback (e.g., "This is one of the worst fashion choices I have seen in my life" and "What bad taste!", i.e., the anger-induced group). Previous research has shown that this procedure makes participants angry [11]. The other half of the participants received positive feedback (e.g., "This is one of the best fashion choices I have seen in my life.", i.e., the nonanger-induced group).

\subsection{Aggressive Behavior}

The hot sauce paradigm was used to measure aggressive behavior [31]. The participants were randomly assigned to play the role of "food administrator" in the experiment; they prepared a dish of rice for the same ostensible peer in the other room, who played the role of "food taster". Then, the participants were provided with a dish of rice and four bottles of sauces and were told that they could put a sauce on the rice, that they could choose the heat intensity of the sauce (ranging from least hot (1) to extremely hot (4)) and that the food taster (e.g., the peer who criticized their images choices) hates spicy food [32]. The participants were also told that they could not blend the sauces and that the peer must consume the complete amount of sauced rice on the dish. In addition, the subjects could choose to taste how hot the sauces were before choosing one by using a small spoon. The researcher left the room for five minutes and then returned to take the dish of sauce to the peer. A digital scale was used to measure the differences between the quantities of sauces used. This paradigm is a wellvalidated measure of aggression [33]. Aggressive behavior was calculated by multiplying the hotness of the sauce selected by the weight in grams [34].

\subsection{Procedures and Analysis}

The participants were tested individually. They were told that the research was based on studying the relationship between women's taste in fashion and emotions. Upon their arrival, the participants completed a consent form. Then, the ZKA-PQ scale and the trait anger scale of the BPAQ were completed. Afterwards, the participants were induced emotionally by providing them with feedback on their choice of fashion style rankings based on the images shown to them. Then, they completed the hot sauce paradigm to measure their aggressive behavior. Finally, a suspiciousness questionnaire was given that assessed whether the participants knew the true purposes of the study before being debriefed, they were asked the following three questions: Did you know the true objective of the study? Have other students talked to you about this study? Were you aware of any deception? None of the participants expressed suspicion regarding the true objectives of the experiment. Participants were thanked for their participation and fully debriefed. All the administered questionnaires were translated into Arabic. All the analyses were carried out using Statistical Package for the Social Sciences (SPSS) 26.0 [35].

\section{RESULTS}

\subsection{Correlations Between Personality Traits, Anger, and Aggressive Behavior}

Table 1A and B shows the correlation coefficient among the five personality factors and their facets, trait anger and aggressive behavior for nonanger and anger groups. As can be seen in Table $\mathbf{1 A}$ and $\mathbf{B}$, the majority of aggressiveness facets were positively correlated with trait anger for nonanger and anger groups. Whereas, the majority of neuroticism facets were positively correlated with trait anger for nonanger group (Table 1B). None of the facets of personality traits neither the trait anger were significantly correlated with aggressive behavior for nonanger and anger groups. All other correlations are presented in Table $\mathbf{1 A}$ and $\mathbf{B}$.

\subsection{Between-Group Analysis}

An independent-samples t-test was conducted to compare aggressive behavior in the anger and nonanger groups. As seen in Fig. (1), the participants who had been criticized for their fashion choices had higher hot sauce paradigm scores than those of the participants who received positive feedback [(nonanger group; $M=2.84, S D=1.41$ and anger group $M=$ $4.11, S D=2.30), t(46)=-2.30, p=0.03, d=0.66]$.

Table 1A. Correlation between personality traits, trait anger, and aggressive behavior for the non-anger group.

\begin{tabular}{|c|c|c|c|c|c|c|c|c|c|c|c|c|c|c|c|c|c|c|c|c|c|c|c|c|c|c|}
\hline & AG2 & AG3 & AG4 & AG & AC1 & AC2 & AC3 & AC4 & AC & EX1 & EX2 & EX3 & EX4 & EX & NE1 & NE2 & NE3 & NE4 & NE & SS1 & SS2 & SS3 & SS4 & SS & TA & AB \\
\hline AG1 & $.654 * *$ & \begin{tabular}{|l|}
0.358 \\
\end{tabular} & 0.412 & .735** & \begin{tabular}{|c|}
-0.198 \\
\end{tabular} & \begin{tabular}{|l|}
-0.259 \\
\end{tabular} & $.430 *$ & \begin{tabular}{|l|}
-0.264 \\
\end{tabular} & \begin{tabular}{|c|}
-0.113 \\
\end{tabular} & -0.133 & -0.342 & 0.294 & \begin{tabular}{|l|}
-0.12 \\
\end{tabular} & -0.128 & 0.255 & 0.241 & 0.4 & -0.113 & 0.182 & $.451 *$ & 0.392 & 0.252 & 0.356 & .502* & $.482 *$ & 0.202 \\
\hline AG2 & & $|.757 * *|$ & .708** & \begin{tabular}{|l|}
$.931 * *$ \\
\end{tabular} & $\mid-0.401$ & $-.640^{* * *}$ & \begin{tabular}{|l|} 
\\
\end{tabular} & $\mid$\begin{tabular}{|c|}
-0.367 \\
\end{tabular} & \begin{tabular}{|l|}
-0.41 \\
\end{tabular} & $-.433 *$ & $\begin{array}{l}.438 * \\
\end{array}$ & 0.166 & -0.354 & \begin{tabular}{|l|l|}
-0.428 \\
\end{tabular} & $.506 *$ & $.621 * *$ & $\mid .556^{* * *}$ & \begin{tabular}{|l|}
0.345 \\
\end{tabular} & $.617^{* *}$ & \begin{tabular}{|l|}
0.016 \\
\end{tabular} & $.510^{*}$ & \begin{tabular}{|l|}
0.161 \\
\end{tabular} & \begin{tabular}{|l|l|}
$.564 * *$ \\
\end{tabular} & \begin{tabular}{|l|}
0.318 \\
\end{tabular} & $.632 * *$ & -0.065 \\
\hline AG3 & & & $.673 * *$ & $.843 * *$ & \begin{tabular}{|l|}
-0.402 \\
\end{tabular} & \begin{tabular}{|c|}
$-.454 *$ \\
\end{tabular} & 0.244 & \begin{tabular}{|l|}
-0.383 \\
\end{tabular} & \begin{tabular}{|l|}
-0.398 \\
\end{tabular} & $-.451^{*}$ & $-.431 *$ & -0.086 & -0.355 & $-.500 *$ & $.562 *$ & $.788^{* *}$ & $.530^{* *}$ & \begin{tabular}{|l|l|}
$.488^{*}$ \\
\end{tabular} & $.726 * *$ & -0.188 & \begin{tabular}{|l|l|}
0.411 \\
\end{tabular} & -0.068 & $.515^{*}$ & 0.131 & $.609 * *$ & 0.189 \\
\hline AG4 & & & & $.820 * *$ & -0.169 & -0.327 & 0.305 & \begin{tabular}{|l|}
-0.254 \\
\end{tabular} & \begin{tabular}{|l|}
-0.224 \\
\end{tabular} & $-.645 * *$ & $-.718^{* * *}$ & -0.015 & -0.345 & $-.653 * *$ & . $767 * * \mid$ & \begin{tabular}{|l|l|}
$.807 * *$ \\
\end{tabular} & \begin{tabular}{|l|l|}
$.483 *$ \\
\end{tabular} & \begin{tabular}{|l|l|} 
\\
\end{tabular} & $.831 * *$ & -0.307 & 0.145 & 0.154 & $.414 *$ & \begin{tabular}{|l|}
-0.007 \\
\end{tabular} & \begin{tabular}{|l|l|}
$.561 * *$ \\
\end{tabular} & 0.014 \\
\hline $\mathrm{AG}$ & & & & & $\mid-0.351$ & \begin{tabular}{|l|}
$-.489 *$ \\
\end{tabular} & \begin{tabular}{|l|}
0.37 \\
\end{tabular} & \begin{tabular}{|c|}
-0.366 \\
\end{tabular} & \begin{tabular}{|l|}
-0.33 \\
\end{tabular} & $-.458^{*}$ & -.559 ** & 0.096 & -0.386 & \begin{tabular}{|l|l|}
$-.492 *$ \\
\end{tabular} & $616^{* * *}$ & $.784 * *$ & \begin{tabular}{|l|l|}
$.594 * *$ \\
\end{tabular} & \begin{tabular}{|l|}
0.369 \\
\end{tabular} & $.703 * *$ & 0.011 & 0.426 & 0.11 & $\mid 550$ ** & \begin{tabular}{|l|}
0.281 \\
\end{tabular} & . $688 * *$ & \begin{tabular}{|l|}
-0.003 \\
\end{tabular} \\
\hline $\mathrm{ACl}$ & & & & & & $.568^{* *}$ & 0.136 & .607** & $.840^{* * *}$ & $.462 *$ & 0.237 & -0.252 & 0.166 & \begin{tabular}{|l|}
0.263 \\
\end{tabular} & -0.135 & -0.226 & \begin{tabular}{|c|}
-0.024 \\
\end{tabular} & \begin{tabular}{|c|}
-0.036 \\
\end{tabular} & \begin{tabular}{|l|}
-0.122 \\
\end{tabular} & \begin{tabular}{|l|}
-0.049 \\
\end{tabular} & $-.525 *$ & 0.006 & \begin{tabular}{|l|}
-0.231 \\
\end{tabular} & \begin{tabular}{|l|}
-0.175 \\
\end{tabular} & -0.18 & -0.107 \\
\hline $\mathrm{AC} 2$ & & & & & & & 0.102 & \begin{tabular}{|l|}
0.421 \\
\end{tabular} & . $707^{* *}$ & 0.167 & 0.071 & -0.419 & 0.104 & 0.029 & \begin{tabular}{l|l|}
0.114 \\
\end{tabular} & -0.281 & \begin{tabular}{|c|}
-0.377 \\
\end{tabular} & \begin{tabular}{|c|}
-0.025 \\
\end{tabular} & \begin{tabular}{|l|}
-0.008 \\
\end{tabular} & -0.018 & $-.652 * *$ & -0.252 & \begin{tabular}{|c|}
-0.31 \\
\end{tabular} & \begin{tabular}{|l|}
-0.299 \\
\end{tabular} & \begin{tabular}{|l|}
-0.223 \\
\end{tabular} & -0.028 \\
\hline $\mathrm{AC} 3$ & & & & & & & & \begin{tabular}{|l|}
0.193 \\
\end{tabular} & $.499 *$ & -0.017 & -0.118 & 0.094 & $.433 *$ & 0.151 & 0.269 & \begin{tabular}{|l|}
0.099 \\
\end{tabular} & \begin{tabular}{|l|}
0.032 \\
\end{tabular} & 0.021 & \begin{tabular}{|l}
-0.007 \\
\end{tabular} & .493* & 0.187 & $.522 *$ & \begin{tabular}{|l|l|}
0.166 \\
\end{tabular} & $.546^{*}$ & 0.295 & -0.125 \\
\hline $\mathrm{AC4}$ & & & & & & & & & $.770^{* * *}$ & $.500^{*}$ & $\begin{array}{l}.426^{*} \\
\end{array}$ & -0.004 & 0.175 & \begin{tabular}{|l|}
0.401 \\
\end{tabular} & -0.192 & \begin{tabular}{|l|}
-0.228 \\
\end{tabular} & \begin{tabular}{|c|}
-0.089 \\
\end{tabular} & \begin{tabular}{|l|l|}
0.111 \\
\end{tabular} & \begin{tabular}{|l|}
-0.024 \\
\end{tabular} & 0.078 & \begin{tabular}{|l|}
$-.473 *$ \\
\end{tabular} & \begin{tabular}{|c|}
-0.077 \\
\end{tabular} & $\mid-0.316$ & \begin{tabular}{|c|}
-0.147 \\
\end{tabular} & \begin{tabular}{|l|}
0.002 \\
\end{tabular} & \begin{tabular}{|c|}
-0.173 \\
\end{tabular} \\
\hline $\mathrm{AC}$ & & & & & & & & & & 0.386 & 0.36 & -0.214 & 0.31 & 0.295 & -0.055 & \begin{tabular}{|l|}
-0.324 \\
\end{tabular} & $\mid$\begin{tabular}{|c|}
-0.221 \\
\end{tabular} & \begin{tabular}{|l|l|}
0.106 \\
\end{tabular} & \begin{tabular}{|l|l|}
-0.113 \\
\end{tabular} & \begin{tabular}{|l|}
0.378 \\
\end{tabular} & -0.439 & \begin{tabular}{|l|l|}
0.066 \\
\end{tabular} & \begin{tabular}{|l|}
-0.292 \\
\end{tabular} & \begin{tabular}{|l|l|}
0.136 \\
\end{tabular} & \begin{tabular}{|c|}
-0.042 \\
\end{tabular} & \begin{tabular}{|l|}
-0.04 \\
\end{tabular} \\
\hline EX1 & & & & & & & & & & & $.739 * *$ & 0.311 & 0.316 & $.828^{* * *}$ & \begin{tabular}{|l|}
-0.379 \\
\end{tabular} & \begin{tabular}{|l|l|}
$-.457 *$ \\
\end{tabular} & \begin{tabular}{|l|}
0.037 \\
\end{tabular} & \begin{tabular}{|l|}
-0.229 \\
\end{tabular} & \begin{tabular}{|l|}
-0.331 \\
\end{tabular} & 0.257 & -0.199 & 0.07 & -0.2 & 0.139 & \begin{tabular}{|c|}
-0.096 \\
\end{tabular} & -0.271 \\
\hline EX2 & & & & & & & & & & & & \begin{tabular}{|l|}
0.131 \\
\end{tabular} & \begin{tabular}{|l|}
0.277 \\
\end{tabular} & \begin{tabular}{|l}
$.784 * *$ \\
\end{tabular} & \begin{tabular}{|c|}
$-.504 *$ \\
\end{tabular} & \begin{tabular}{|l|l|}
-.537 \\
\end{tabular} & $\mid$\begin{tabular}{|c|}
-0.065 \\
\end{tabular} & $\mid$\begin{tabular}{|c|}
-0.217 \\
\end{tabular} & \begin{tabular}{|l|l|}
-0.369 \\
\end{tabular} & 0.163 & \begin{tabular}{|l|}
-0.135 \\
\end{tabular} & \begin{tabular}{|c|}
-0.143 \\
\end{tabular} & \begin{tabular}{|c|}
-0.417 \\
\end{tabular} & \begin{tabular}{|l|l|}
0.025 \\
\end{tabular} & $\mid-0.161$ & $\mid-0.009$ \\
\hline EX3 & & & & & & & & & & & & & 0.235 & \begin{tabular}{|l|}
$.558^{*}$ \\
\end{tabular} & -0.295 & -0.122 & \begin{tabular}{|l|}
0.239 \\
\end{tabular} & \begin{tabular}{|l|}
-0.29 \\
\end{tabular} & \begin{tabular}{|l|}
-0.294 \\
\end{tabular} & 0.11 & 0.176 & $.457 *$ & \begin{tabular}{|l|}
-0.205 \\
\end{tabular} & \begin{tabular}{|l|}
0.077 \\
\end{tabular} & \begin{tabular}{|l|}
0.219 \\
\end{tabular} & -0.373 \\
\hline EX4 & & & & & & & & & & & & & & $.690^{* *}$ & -0.399 & $-.543 * *$ & \begin{tabular}{|c|}
-0.324 \\
\end{tabular} & \begin{tabular}{|c|}
$-.433 *$ \\
\end{tabular} & $-.638 * *$ & 0.297 & -0.025 & $.584 * *$ & \begin{tabular}{|c|}
-0.243 \\
\end{tabular} & \begin{tabular}{|l|l|}
0.317 \\
\end{tabular} & $\mid-0.311$ & $\mid-0.143$ \\
\hline EX & & & & & & & & & & & & & & & \begin{tabular}{|c|}
$-.575^{*}$ \\
\end{tabular} & $-.663^{* * *}$ & \begin{tabular}{|l|}
-0.08 \\
\end{tabular} & \begin{tabular}{|l|}
$-.480 *$ \\
\end{tabular} & $-.628^{*}$ & 0.301 & -0.142 & 0.354 & \begin{tabular}{|c|}
-0.395 \\
\end{tabular} & 0.225 & \begin{tabular}{|c|}
-0.173 \\
\end{tabular} & -0.293 \\
\hline
\end{tabular}




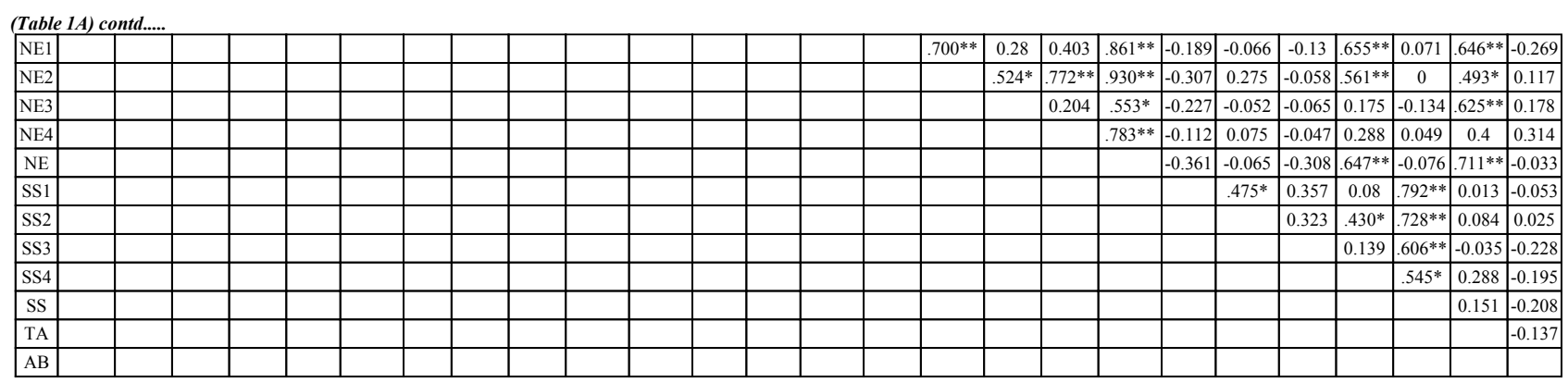

Table 1B. Correlation between personality traits, trait anger, and aggressive behavior for the anger group.

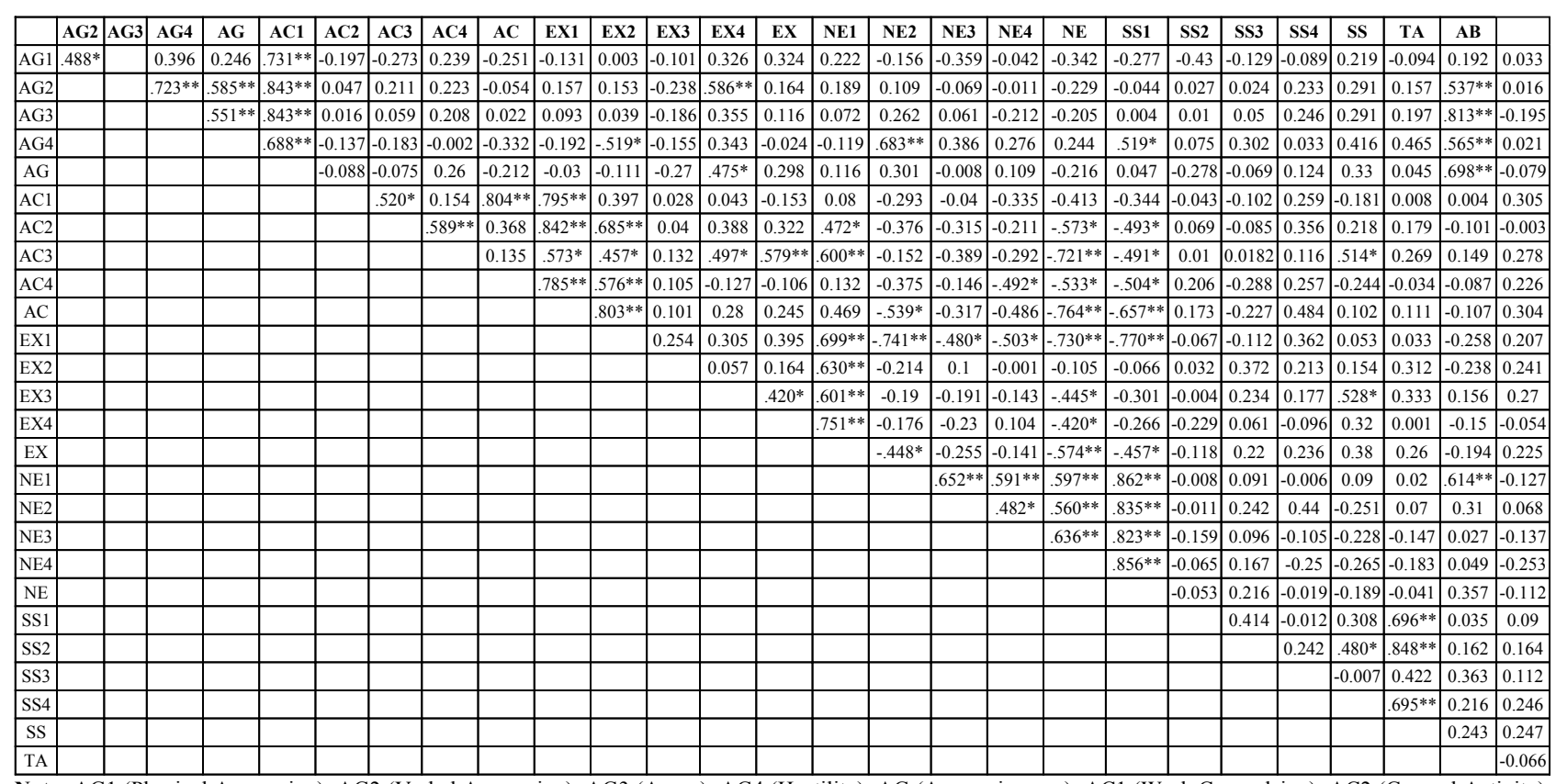

Note: AG1 (Physical Aggression); AG2 (Verbal Aggression); AG3 (Anger); AG4 (Hostility); AG (Aggressiveness); AC1 (Work Compulsion); AC2 (General Activity); AC3 (Restlessness); AC4 (Work Energy); AC (Activity); EX1 (Positive Emotions); EX2 (Social Warmth); EX3 (Exhibitionism); EX4 (Sociability); EX (Extraversion); NE1 (Anxiety); NE2 (Depression); NE3 (Dependency); NE4 (Low self-esteem); NE (Neuroticism); SS1 (Thrill and Adventure Seeking); SS2 (Experience Seeking), SS3 (Disinhibition); SS4 (Boredom Susceptibility/ Impulsivity); SS (Sensation Seeking); TA; (Trait Anger); AB (Aggressive Behavior).

To test whether personality traits and trait anger interact with the induction content in regard to eliciting aggressive behavior, separate one-way ANCOVAs were performed with each group (anger vs nonanger) as the independent factor and one of the personality traits and the anger trait as the covariates.

The results showed that the tests for equality of the regression slopes for the two levels of the group variable were not significant for each of the six one-way ANOVAs (Table 2). Thus, the effect of the group on aggressive behavior is not moderated by personality traits and anger traits.

\section{DISCUSSION}

This investigation explored whether situational influence, in which subjects are made to feel angry, is more likely to influence aggressive behavior than personality traits. Compared with previous studies that have been conducted, our investigation indeed supports the notion that situational prompts, such as being provoked by others can lead to aggressive behavior [36]. This investigation found that participants who have been negatively criticized for their taste in fashion do, in fact, become more aggressive in the form of scoring higher on the hot sauce paradigm. These findings are in line with other studies that have found interpersonal insults to be a key driving factor leading to aggression [11].

The present study shows no significant correlation between aggression and any facets of personality traits, whereas other studies have shown connections with neuroticism, agreeableness, conscientiousness, and impulsiveness [6, 7]. However, our study is the first to assess the correlation between the facets of the ZKA-PQ and aggressive behavior.

The data from this research yield several practical implications. Firstly, our results show that an individual's behavior is affected by one's emotional state. Therefore, clinical psychologists should consider the individual emotional state when developing psychological assessments. Additionally, our research suggests that anger induces aggressive behavior. Consequently, experimental psychologists should consider this negative emotion as it could affect participants' responses when conducting experimental research. 
Table 2. ANCOVA summary table for the equality of regression slopes among anger and non-anger group when introducing personality traits and anger trait.

\begin{tabular}{|c|c|c|c|c|c|}
\hline \multirow[t]{2}{*}{ Covariates } & \multicolumn{2}{|c|}{ LS means after controlling for the covariate } & \multirow{2}{*}{$\frac{\text { Equality test between slopes }}{F}$} & \multirow[b]{2}{*}{$p$} & \multirow[b]{2}{*}{$\eta^{2}$} \\
\hline & Anger group & Non-anger group & & & \\
\hline Sensation-seeking & $\begin{array}{l}3.896 \\
(2.417)\end{array}$ & $\begin{array}{c}2.896 \\
(1.470)\end{array}$ & 1.982 & 0.17 & 0.054 \\
\hline Aggressiveness & $\begin{array}{c}4.374 \\
(2.254) \\
\end{array}$ & $\begin{array}{c}2.864 \\
(1.439) \\
\end{array}$ & 0.100 & 0.75 & 0.003 \\
\hline Activity & $\begin{array}{c}4.177 \\
(2.488) \\
\end{array}$ & $\begin{array}{c}2.845 \\
(1.368) \\
\end{array}$ & 1.472 & 0.23 & 0.043 \\
\hline Extraversion & $\begin{array}{c}4.155 \\
(2.345) \\
\end{array}$ & $\begin{array}{c}2.955 \\
(1.462) \\
\end{array}$ & 2.419 & 0.13 & 0.058 \\
\hline Neuroticism & $\begin{array}{r}4.170 \\
(2.332) \\
\end{array}$ & $\begin{array}{c}2.762 \\
(1.540) \\
\end{array}$ & 0.064 & 0.80 & 0.002 \\
\hline Tait Anger & $\begin{array}{l}4.108 \\
(2.305)\end{array}$ & $\begin{array}{c}2.840 \\
(1.412)\end{array}$ & 0.010 & 0.92 & 0.001 \\
\hline
\end{tabular}

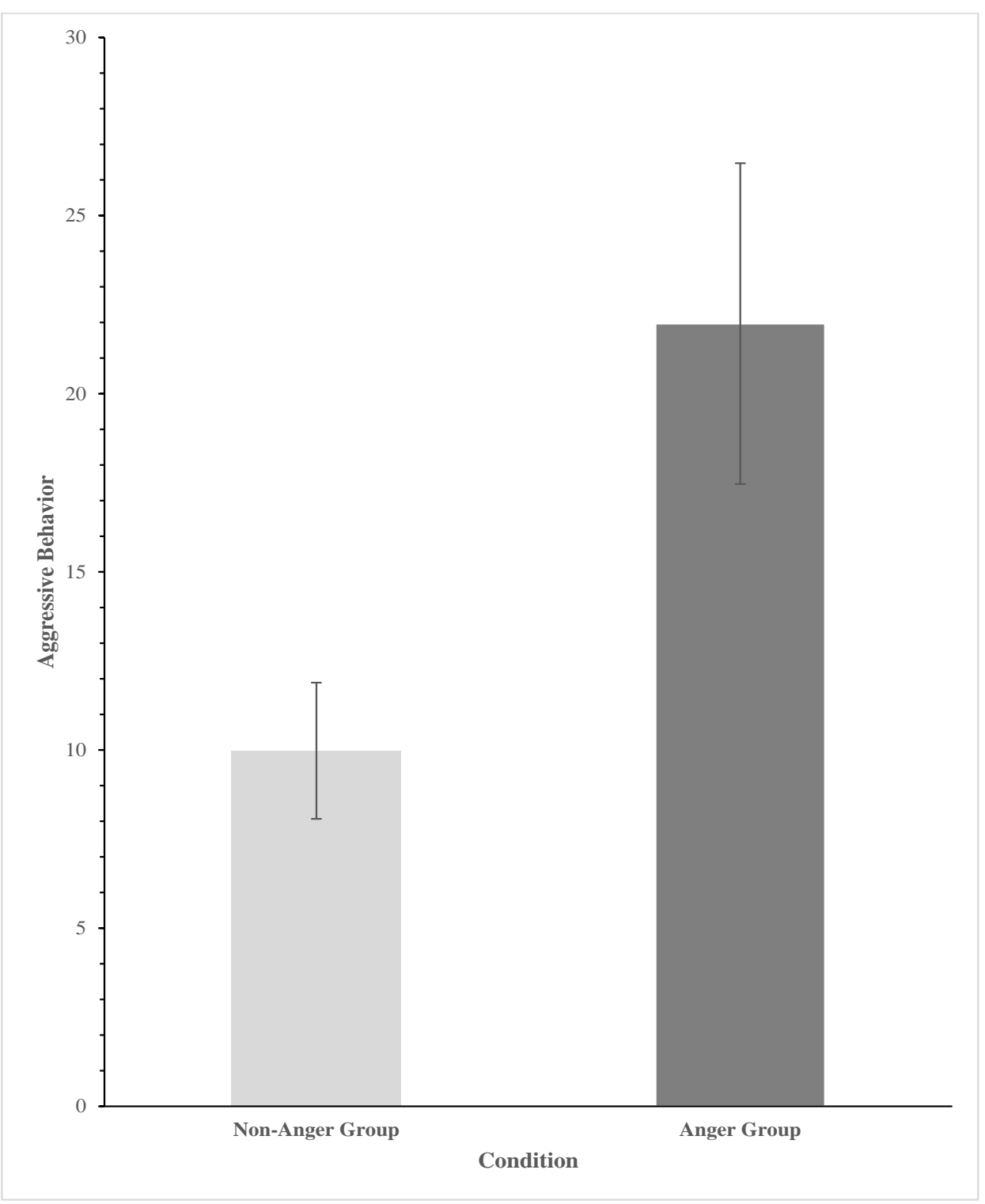

Fig. (1). Difference between anger and nonanger groups in aggressive behavior. 
The present study, like all studies, has limitations. Firstly, the limited sample size $(N=48)$ and the use of only women participants impede the generalizability of the current findings. Secondly, we did not include a measure of state anger to conclude that aggressive behavior is due to state anger and not the other mechanisms. In the present study, we used an interpersonal insult as the negative social feedback due to the proven effectiveness of this technique shown by previous studies in inducing anger emotion [29]. Research has shown that insulted participants significantly differ from noninsulted participants only in anger emotion but not in fear or positive affect. The state-induced anger by this interpersonal insult is associated with a relative left-prefrontal activity. This activity is, in turn, related to aggressive behavior [37].

Furthermore, no measure of the participants' emotional states was taken before or after the experiment to determine how the subjects were feeling. Therefore, the findings do not account for whether the participants may have already been experiencing stress or anxiety. In addition, from a biological perspective, it is well known that high levels of estradiol and progesterone hormones reduce aggression in women [38]. It would be interesting to verify the moderating role of these hormones on the level of aggression expressed by our participants.

The present research has taken into consideration both situational and personality factors and supports the argument that situational factors are a greater predictor of aggressive behavior. Due to its harmful consequences, the continuity of research on the determinants of aggression is vitally important, as intervention and prevention program activities for reducing aggression focus primarily on training individuals to interpret provocation stimuli nonaggressively and on the regulation of anger in response to that provocation.

\section{CONCLUSION}

The present research shows that the situation is more influential than a person's personality in predicting aggressive behavior. The participants' anger state, triggered by an interpersonal insult, played a more important role than that of their personality traits and trait anger in producing aggressive behavior. The angry participants allocated more hot sauce to a targeted person who criticized their opinion. However, this allocation was not related to the participants' personality traits or trait anger. As an emotion with interacting physiological and cognitive mechanisms [39], further research is needed to assess the potential mediators of the anger-aggression link.

\section{ETHICS APPROVAL AND CONSENT TO PARTI- CIPATE}

This study has been approved by the Research Ethics Committee of Qatar University, Doha, Qatar under ethical approval no. (QU-IRB 1361-EA/20).

\section{HUMAN AND ANIMAL RIGHTS}

No Animals were used in this research. All human research procedures followed were in accordance with the ethical standards of the committee responsible for human experimentation (institutional and national), and with the
Helsinki Declaration of 1975, as revised in 2013.

\section{CONSENT FOR PUBLICATION}

Informed consent was obtained from all the patients when they were enrolled.

\section{AVAILABILITY OF DATA AND MATERIALS}

The data that support the findings of this study are available from the corresponding author (Y.H) upon reasonable request.

\section{FUNDING}

None.

\section{CONFLICT OF INTEREST}

The authors declare no conflict of interest, financial or otherwise.

\section{ACKNOWLEDGEMENTS}

The research team thanks Mr. Yousif Saleh Mahdi for editing the research paper.

\section{REFERENCES}

[1] Baumeister R, Bushman BJ, Campbell W. Self-esteem, narcissism, and aggression. Curr Dir Psychol Sci 2000; 9: 26-9. [http://dx.doi.org/10.1111/1467-8721.00053]

[2] Bushman BJ, Huesmann LR. Aggression.Handbook of social psychology. 5th ed. New York: John Wiley \& Sons 2010; pp. 833-63. [http://dx.doi.org/10.1002/9780470561119.socpsy002023]

[3] Berkowitz L. On the formation and regulation of anger and aggression. A cognitive-neoassociationistic analysis. Am Psychol 1990; 45(4): 494-503.

[http://dx.doi.org/10.1037/0003-066X.45.4.494] [PMID: 2186678]

[4] Anderson CA, Bushman BJ. Human aggression. Annu Rev Psychol 2002; 53: $27-51$.

[http://dx.doi.org/10.1146/annurev.psych.53.100901.135231] [PMID: 11752478]

[5] Allen JJ, Anderson CA. General aggression model.International Encyclopedia of Media Effects. New York: John Wiley \& Sons 2017; pp. 1-15.

[http://dx.doi.org/10.1002/9781118783764.wbieme0078]

[6] Jones S, Miller J, Lynam D. Personality, antisocial behavior, and aggression: A meta-analytic review. J Crim Justice 2011; 39: 329-37. [http://dx.doi.org/10.1016/j.jcrimjus.2011.03.004]

[7] Sharpe J, Desai S. The Revised Neo Personality Inventory and the MMPI-2 Psychopathology Five in the prediction of aggression. Pers Individ Dif 2001; 31: 505-18.

[http://dx.doi.org/10.1016/S0191-8869(00)00155-0]

[8] Bettencourt BA, Talley A, Benjamin AJ, Valentine J. Personality and aggressive behavior under provoking and neutral conditions: A metaanalytic review. Psychol Bull 2006; 132(5): 751-77.

[http://dx.doi.org/10.1037/0033-2909.132.5.751] [PMID: 16910753]

[9] Anderson C, Deuser W, DeNeve K. Hot temperatures, hostile affect, hostile cognition, and arousal: Tests of a general model of affective aggression. Pers Soc Psychol Bull 1995; 21: 434-48.

[http://dx.doi.org/10.1177/0146167295215002]

[10] Berkowitz L. Aggression: Its causes, consequences, and control. New York: McGraw-Hill Book Company 1993.

[11] Hasan Y, Eldous H, Khalily H. Moderating role of narcissism in the effects of anger induction on aggression. Researches Cognitives 2019; 11: 1-19.

[12] Leary MR, Twenge JM, Quinlivan E. Interpersonal rejection as a determinant of anger and aggression. Pers Soc Psychol Rev 2006; 10(2): 111-32.

[http://dx.doi.org/10.1207/s15327957pspr1002_2] [PMID: 16768650]

[13] Twenge JM, Campbell WK. "Isn't it fun to get the respect that we're going to deserve?" Narcissism, social rejection, and aggression. Pers Soc Psychol Bull 2003; 29(2): 261-72. 
[http://dx.doi.org/10.1177/0146167202239051] [PMID: 15272953]

[14] Techer $\mathrm{F}$, Jallais $\mathrm{C}$, Corson $\mathrm{Y}$, et al. Attention and driving performance modulations due to anger state: Contribution of electroencephalographic data. Neurosci Lett 2017; 636: 134-9. [http://dx.doi.org/10.1016/j.neulet.2016.11.011] [PMID: 27826016]

[15] Herrero N, Gadea M, Rodríguez-Alarcón G, Espert R, Salvador A. What happens when we get angry? Hormonal, cardiovascular and asymmetrical brain responses. Horm Behav 2010; 57(3): 276-83. [http://dx.doi.org/10.1016/j.yhbeh.2009.12.008] [PMID: 20045413]

[16] Yip JA, Schweitzer ME. Mad and misleading: Incidental anger promotes deception. Organ Behav Hum Decis Process 2016; 137: 207-17.

[http://dx.doi.org/10.1016/j.obhdp.2016.09.006]

[17] Hendricks L, Bore S, Aslinia D, Morriss G. The effects of anger on the brain and body. Nat Forum J Counsell Addic. 2: 1-12.

[18] Nederlof A, Muris P, Hovens JE. Anger, anxiety, and feelings of delusional threat as predictors of aggressive attitudes: An experimental mood induction study in a non-clinical sample. Pers Individ Dif 2014; 57: $25-30$.

[http://dx.doi.org/10.1016/j.paid.2013.09.006]

[19] Cabral JCC, Almeida RMMD. Effects of anger on dominance-seeking and aggressive behaviors. Evol Hum Behav 2019; 40: 23-33.

[http://dx.doi.org/10.1016/j.evolhumbehav.2018.07.006]

[20] Lench HC, Flores SA, Bench SW. Discrete emotions predict changes in cognition, judgment, experience, behavior, and physiology: a metaanalysis of experimental emotion elicitations. Psychol Bull 2011; 137(5): 834-55.

[http://dx.doi.org/10.1037/a0024244] [PMID: 21766999]

[21] Coan JA, Allen JJB. Handbook of emotion elicitation and assessment. Oxford: Oxford University Press 2007.

[22] Baron RA Richardson DR Human aggression. 2nd ed. New York: Plenum Press 1994.

[23] Hyatt CS, Zeichner A, Miller JD. Laboratory aggression and personality traits: A meta-analytic review. Psychol Violence 2019; 9: 675-89.

[http://dx.doi.org/10.1037/vio0000236]

[24] Krahé B. The social psychology of aggression. 2nd ed. Hove: Psychology Press 2013.

[http://dx.doi.org/10.4324/9780203082171]

[25] Aluja A, Kuhlman M, Zuckerman M. Development of the ZuckermanKuhlman-Aluja Personality Questionnaire (ZKA-PQ): A factor/facet version of the Zuckerman-Kuhlman Personality Questionnaire (ZKPQ). J Pers Assess 2010; 92(5): 416-31.

[http://dx.doi.org/10.1080/00223891.2010.497406] [PMID: 20706928]

[26] Rossier J, Aluja A, Blanch A, et al. Cross-cultural generalizability of the alternative five-factor model using the zuckerman-kuhlman-aluja personality questionnaire. Eur J Pers 2016; 30: 139-57.

[http://dx.doi.org/10.1002/per.2045]

[27] Buss AH, Perry M. The aggression questionnaire. J Pers Soc Psychol
1992; 63(3): 452-9.

[http://dx.doi.org/10.1037/0022-3514.63.3.452] [PMID: 1403624]

[28] Abd-El-Fattah SM. Is the aggression questionnaire bias free? A rasch analysis. Int Educ J 2007; 18: 237-48.

[29] Hortensius R, Schutter DJ, Harmon-Jones E. When anger leads to aggression: induction of relative left frontal cortical activity with transcranial direct current stimulation increases the anger-aggression relationshipSoc Cogn Affect Neurosci 2012; 7: 342-747.http://dx.doi [http://dx.doi.org/10.1093/scan/nsr012]

[30] Summerell E, Harmon-Jones C, Kelley NJ, Peterson CK, KrstanoskaBlazeska K, Harmon-Jones E. Does cognitive broadening reduce anger? Front Psychol 2019; 9: 2665.

[http://dx.doi.org/10.3389/fpsyg.2018.02665] [PMID: 30671003]

[31] Lieberman J, Solomon S, Greenberg J, McGregor H. A hot new way to measure aggression: Hot sauce allocation. Aggress Behav 1999; 25: 331-48.

[http://dx.doi.org/10.1002/(SICI)1098-2337(1999)25:5<331::AID-AB 2>3.0.CO;2-1]

[32] Barlett C, Branch O, Rodeheffer C, Harris R. How long do the shortterm violent video game effects last? Aggress Behav 2009; 35(3): 225-36.

[http://dx.doi.org/10.1002/ab.20301] [PMID: 19206102]

[33] Adachi P, Willoughby T. The effect of video game competition and violence on aggressive behavior: Which characteristic has the greatest influence? Psychol Violence 2011; 1: 259-74.

[http://dx.doi.org/10.1037/a0024908]

[34] Saleem M, Anderson CA, Barlett CP. Assessing helping and hurting behaviors through the Tangram help/hurt task. Pers Soc Psychol Bull 2015; 41(10): 1345-62.

[http://dx.doi.org/10.1177/0146167215594348] [PMID: 26199219]

[35] Corp IBM. IBM SPSS Statistics for Windows, Version 260. Armonk, NY: IBM Corp 2019.

[36] Anderson CA, Shibuya A, Ihori N, et al. Violent video game effects on aggression, empathy, and prosocial behavior in eastern and western countries: a meta-analytic review. Psychol Bull 2010; 136(2): 151-73. [http://dx.doi.org/10.1037/a0018251] [PMID: 20192553]

[37] Harmon-Jones E, Sigelman J. State anger and prefrontal brain activity: evidence that insult-related relative left-prefrontal activation is associated with experienced anger and aggression. J Pers Soc Psychol 2001; 80(5): 797-803.

[http://dx.doi.org/10.1037/0022-3514.80.5.797] [PMID: 11374750]

[38] Denson TF, O'Dean SM, Blake KR, Beames JR. Aggression in women: Behavior, brain and hormones. Front Behav Neurosci 2018; 12: 81 .

[http://dx.doi.org/10.3389/fnbeh.2018.00081] [PMID: 29770113]

[39] Gannon TA, Ward T, Beech A, Fisher D. Aggressive Offenders' Cognition: Theory, Research and Practice. Sussex: Wiley 2007. [http://dx.doi.org/10.1002/9780470746295]

\section{C) 2020 Hasan \& Eldous.}

This is an open access article distributed under the terms of the Creative Commons Attribution 4.0 International Public License (CC-BY 4.0), a copy of which is available at: (https://creativecommons.org/licenses/by/4.0/legalcode). This license permits unrestricted use, distribution, and reproduction in any medium, provided the original author and source are credited. 